\title{
Alfabetização financeira de estudantes do ensino público no sudoeste do Paraná
}

\author{
Bruna Manoela Albano Acosta ${ }^{(1)}$ \\ Ivanira Correia de Oliveira ${ }^{(2)}$ \\ Queila Franciele Fabris Bosio ${ }^{(3)}$
}

\begin{abstract}
Resumo: Este estudo buscou avaliar a alfabetização financeira de estudantes do curso técnico em Administração do Colégio Estadual de Dois Vizinhos, localizado na região sudoeste do Paraná. Trata-se de pesquisa descritiva, amostragem por conveniência e corte transversal realizada com 44 estudantes. A coleta de dados foi por meio de um questionário estruturado, respondido pelos estudantes presentes na sala de aula nos dias 12 e 13 de agosto de 2019. Os dados foram tratados com estatística básica, para apuração da frequência em percentual. A análise de hábitos financeiros se pautou nas respostas mais adequadas financeiramente, com base na literatura pesquisada, sem atribuição de pontuação. Em conhecimento financeiro, foi atribuído peso 1 para cada questão com resposta correta e 0 para incorreta, utilizando critério OECD/INFE, que recomenda acertos de, no mínimo, 70\% das questões. Os resultados mostraram que os estudantes de modo geral possuíam bons hábitos para compras e controle do orçamento pessoal ou familiar. Dois aspectos negativos foram em relação à baixa adesão a seguros e planejamento de aposentadoria, quando a maioria deles afirmou não possuir seguro e encontrar-se despreocupado com a aposentadoria. Quanto ao conhecimento financeiro, o nível de acertos foi de $56 \%$, uma vez que $75 \%$ a $98 \%$ dos estudantes acertou cinco entre nove questões apresentadas. Considerando este nível de acertos para conhecimento financeiro, os resultados positivos e outros que precisam ser melhorados em hábitos financeiros, avalia-se que os estudantes ainda necessitam adquirir novos conhecimentos e hábitos financeiros para se tornarem efetivamente alfabetizados financeiramente.
\end{abstract}

Palavras-chave: Conhecimento financeiro. Finanças pessoais. Hábitos financeiros.

\section{Financial literacy of public teaching students in the Southwest of Paraná}

\begin{abstract}
The objective of this study was to evaluate the financial literacy of Adminstrative technician students from Colégio Estadual de Dois Vizinhos, located in the Southwest of Paraná. This is a descriptive research, convenience and cross-sectional sampling with 44 students. Data collection through a questionnaire answered by students who were present in the classroom on August 12 and 13, 2019. The analysis of the financial habits was defined on the most financial appropriate answers, based on the researched literature, with no punctuation attribution. In Financial knowledge, the weight of 1 was assigned to each question with a correct answer, and 0 to an incorrect one, using the OECD/INFE critery, which recommends correct answers for at least $70 \%$ of the questions. The results showed that students in general have good shopping habits and control of their personal or family budget. Two negative aspects were in relation to the low adherence to insurance and retirement planning, when most

\footnotetext{
${ }^{1}$ Graduada em Administração pela Universidade Estadual do Oeste do Paraná, campus de Francisco Beltrão. E-mail: brunamalbano16@gmail.com.

${ }^{2}$ Graduada em Administração pela Universidade Estadual de Maringá, mestre em Engenharia de Produção pela Universidade Federal de Santa Catarina. Professora na Universidade Estadual do Oeste do Paraná, campus de Francisco Beltrão. E-mail: ivanira.oliveira@unioeste.br.

${ }^{3}$ Graduada em Ciências Contábeis pela Faculdade Educacional de Dois Vizinhos, doutoranda em Desenvolvimento Regional pela Universidade Tecnológica Federal do Paraná. Professora na Universidade Estadual do Oeste do Paraná, campus de Francisco Beltrão. E-mail: queilafabris@gmail.com.
} 
respondents stated that they did not have insurance and unconcern about retirement. As for financial knowledge, the level of correct answers was $56 \%$, given that $75 \%$ to $98 \%$ of the students answered correctly five of the nine questions presented. Considering that the research shows positive results and others need to be improved in Financial Habits, it is estimated that students still need to acquire new knowledge and financial habits in order to become effectively financially literate.

Key Works: Financial knowledge. Personal finances. Financial Habits

\section{Introdução}

A evolução rápida do mercado, principalmente do mercado financeiro, e a transferência de responsabilidades e riscos para os cidadãos tornou a educação financeira uma ferramenta importante para aumentar o conhecimento, habilidades e atitudes, melhorando o nível de alfabetização financeira (LUSARDI, 2012; OECD, 2015). A alfabetização financeira constrói uma sociedade mais resiliente financeiramente, em que cidadãos são capazes de superar crises que afetam as finanças pessoais (LUSARDI, HASLER, YAKOBOSKI, 2020).

Cada vez mais as pessoas precisam utilizar instrumentos de gestão financeira, avaliar oportunidades e riscos de financiamentos e de investimentos, mostrando-se cogente, igualmente, a tomada de decisões em relação ao consumo, à proteção da vida e ao patrimônio. Para tanto, torna-se indispensável ter conhecimento financeiro e utilizá-lo de maneira adequada para obter melhores resultados. Segundo Huston (2010), a capacidade de entendimento e uso de informações relacionadas às finanças pessoais é definida como alfabetização financeira. Entretanto, o fenômeno é complexo devido às influências externas que afetam o comportamento individual como, por exemplo: família, comunidade, crenças e preconceitos.

A partir da crise financeira global de 2008, a preocupação com a educação financeira levou a Organisation for Economic Co-operation and Development (OECD) ao lançamento, em 2009, de um trabalho sobre estratégias nacionais de educação financeira que serviria como instrumento político para os países (OECD, 2015). No Brasil, a educação financeira tornou-se política pública com o Decreto Federal no 7.397/2010, que instituiu a Estratégia Nacional de Educação Financeira (ENEF) para promover a educação financeira, contribuir para fortalecer o sistema financeiro nacional e a consciência de consumidores (BRASIL, 2010).

Publicado em 09 de junho de 2020, o Decreto Federal n 10.393/2020 instituiu a nova ENEF com o objetivo de promover a educação financeira, securitária, previdenciária e fiscal. Criou, também, o Fórum Brasileiro de Educação Financeira (FBEF). Esse decreto revogou o anterior (BRASIL, 2020). As autoridades podem monitorar a implementação da estratégia nacional por meio de alfabetização financeira, rastreando mudanças no conhecimento, atitudes e comportamentos. Os resultados possibilitam avaliar a eficácia da estratégia (OECD, 2015). 
Estudos têm buscado encontrar uma forma de avaliar a alfabetização financeira. Entre eles Chen, Volpe (1998); Potrich, Vieira, Chirch (2016). Por outro lado, organizações realizam pesquisas sistemáticas como a OECD e International Network on Financial Education (INFE), que, em 2013, divulgaram pesquisa piloto que mensurou a alfabetização financeira de indivíduos em 14 países (ATKINSON, MESSY, 2013). Também a Teachers Insurance and Annuity Association (TIAA Institute) e Global Financial Literacy Excellence Center (GFLEC) que utilizam, desde 2017, o Personal Finance Index (P-Fin) para determinar o nível de alfabetização financeira de norteamericanos (LUSARDI, HASLER, YAKOBOSKI, 2020).

Motivaram a realização deste estudo a importância do tema para a vida financeira das pessoas e a possibilidade de auxiliar a escola, local da pesquisa, no desenvolvimento de ações a respeito da alfabetização financeira. O objetivo foi avaliar a alfabetização financeira de estudantes do curso técnico em Administração do Colégio Estadual de Dois Vizinhos, sudoeste do Paraná, a partir de hábitos e conhecimento financeiros a respeito de planejamento, orçamento, gestão de crédito e de riscos, poupança e investimentos e aposentadoria.

\section{Educação financeira e alfabetização financeira}

A educação financeira tem sido amplamente comentada e divulgada, principalmente em mídias sociais. No entanto, Hilgert, Hogarth; Beverly (2003) já argumentavam que informação é diferente de educação. A educação é mais ampla, podendo haver uma conjugação de informações, desenvolvimento de habilidades e motivação para fazer as mudanças desejadas no comportamento das pessoas.

A educação financeira é um processo pelo qual consumidores e investidores buscam melhorar a compreensão de conceitos e produtos financeiros a partir da informação, formação e orientação, com vistas ao desenvolvimento de competências e valores necessários à tomada de decisão consciente, considerando oportunidades e riscos, contribuindo de forma consistente para a formação de indivíduos e sociedades (OECD, 2005).

A educação financeira e a alfabetização financeira são termos distintos, no entanto, usualmente são tratadas como termos semelhantes. Porém, a alfabetização financeira é explicada a partir de duas dimensões: entendimento e utilização. O entendimento significa o conhecimento de um indivíduo em finanças pessoais e a utilização refere-se à aplicação desse conhecimento, ou seja, implica que o indivíduo tenha capacidade e confiança para usar seu conhecimento financeiro para tomar decisões financeiras (HUSTON, 2010). 
A alfabetização financeira é um tanto complexa, composta por uma combinação de conhecimentos financeiros, atitudes e comportamentos. Todos precisam ser alfabetizados financeiramente, independentemente do nível de renda e capacidade de investir. A alfabetização financeira contribui, especialmente, para evitar erros financeiros àqueles que vivem com orçamentos apertados (OECD, 2015).

O objetivo da alfabetização financeira é auxiliar os indivíduos na capacitação e educação, a partir de informações relevantes, permitindo segurança em sua vida financeira, além de facilitar a tomada de decisões melhorando o uso de produtos e serviços financeiros (WACHIRA e KIHIU, 2012). Para tomar boas decisões financeiras é necessária uma "combinação de consciência, conhecimento, habilidade, atitude e comportamento" (OECD, 2016, p.49). Segundo Lusardi (2012), governos e empregadores estão transferindo a responsabilidades de tomada de decisão para os indivíduos. Por essa razão, a alfabetização financeira e a capacidade de fazer cálculos são importantes, pois são habilidades necessárias para operar no ambiente econômico com tanta complexidade.

Portanto, a redução de benefícios sociais por parte dos governos, a crescente oferta de crédito, as diversas modalidades de investimentos financeiros, a tentação do consumo despertada pelas mídias sociais e o incentivo ao microempreendedorismo levam os indivíduos a maior exposição ao risco. Nesse caso, ser alfabetizado financeiramente torna-se uma necessidade.

Nesse contexto, é importante mensurar o nível de alfabetização financeira dos indivíduos para desenvolver ações que possam contribuir para melhoria da vida financeira. Chen, Volpe (1998) determinaram o nível de alfabetização de estudantes universitários nos EUA e concluíram que o nível era baixo, uma vez que a maioria dos pesquisados respondeu corretamente apenas $53 \%$ das questões propostas, quando o nível considerado adequado pelos autores seria de 65\%. Potrich, Vieira, Chirch (2016) desenvolveram um indicador que permitisse classificar o nível de alfabetização financeira pesquisando indivíduos no estado do Rio Grande do Sul, Brasil. Os resultados mostraram que a maioria dos entrevistados (68\%) possuía baixo nível de conhecimento financeiro. Segundo os autores, na dimensão comportamento financeiro, o nível foi de mediano a elevado e a atitude financeira não foi decisiva para a classificação.

A OECD/INFE mensura a alfabetização financeira de indivíduos em diversos países. $O$ instrumento de pesquisa foi desenvolvido a partir de pesquisas já existentes (OECD/INFE, 2011). Um indivíduo é tido como alfabetizado financeiramente se atingir o escore de $70 \%$ de respostas corretas, considerando conhecimento financeiro básico, evidências de atitudes financeiras voltadas para o longo prazo e comportamento financeiro para tomar decisões financeiras (OECD/INFE, 2016). Outra pesquisa abrangente avalia a alfabetização nos EUA 
desde 2017, quando foi criado o Personal Finance Index (P-Fin) pelo TIAA/GFLEC (LUSARDI, HASLER, YAKOBOSKI, 2020). Da mesma forma que OECD/INFE, a pesquisa norteamericana considera alfabetizado financeiramente o indivíduo que responde no mínimo $70 \%$ de respostas corretas.

\section{Finanças pessoais}

Finanças pessoais referem-se ao processo de gestão dos recursos de um indivíduo ou de uma família. A gestão financeira pessoal ou familiar objetiva definir estratégias de manutenção e acumulação de bens e valores patrimoniais, visando a tranquilidade econômico-financeira (HALFELD, 2006). É importante que o indivíduo tenha capacidade de gerenciar suas finanças, processar informações econômicas e tomar decisões sobre planejamento financeiro, dívidas, seguros, acumulação de riqueza e aposentadorias (CHEN e VOLPE, 1998; LUSARDI; MITCHELL, 2013). O objetivo do planejamento financeiro é estabelecer estratégias para acumulação de bens e valores que formarão o patrimônio de um indivíduo e/ou família (FRANKENBERG, 1999).

Portanto, o planejamento financeiro é um instrumento importante em finanças pessoais, o qual envolve orçamento, gestão de crédito (dívida), gestão de riscos, poupança e investimentos e o planejamento de aposentadoria. Segundo OECD/INFE (2016), o orçamento é um elemento básico na educação financeira. Ele contribui na gestão do dinheiro, na formação de poupança e na prevenção do endividamento excessivo.

O mercado vem oferecendo cada vez mais produtos e serviços aos consumidores, disponibilizando condições de pagamentos exageradas que podem aumentar a inadimplência. Quanto maior o número de parcelas, maior serão os riscos do não pagamento por parte dos consumidores (LIZOTE; LANA; SIMAS, 2012). Os indivíduos devem estar cientes antes da contratação de um crédito, para não comprometer o orçamento com dívidas e pagamento de altas taxas de juros, sem necessidade (SECURATO, 2002). Portanto, é recomendável avaliar a viabilidade do crédito.

Pessoas com menor grau de alfabetização financeira são mais propensas a contraírem dívidas (SILVA et al., 2017a). Renda baixa e pouca escolaridade são características de pessoas menos alfabetizadas financeiramente (POTRICH; VIEIRA; KIRCH, 2014; SILVA et al. 2017b; LUSARDI, HASLER, YAKOBOSKI, 2020). Em março de 2019, no Brasil, a carteira de empréstimos às pessoas físicas totalizou $\mathrm{R} \$ 1,8$ trilhão, segundo Banco Central do Brasil $(\mathrm{BCB}$, 2019), o que significa pessoas endividadas pagando juros. Ainda no âmbito do crédito, os cartões de crédito e o cheque especial são utilizados com frequência, apesar dos juros mais elevados. Em 
geral, os créditos muitas vezes agravam a situação financeira pela falta de planejamento e controle de gastos.

A grande oferta de crédito, associada ao consumo imediato e ao baixo nível de renda da maior parte da população brasileira, pode levar muitas famílias ao endividamento excessivo, daí a necessidade de melhorar a alfabetização financeira, além de políticas públicas para reduzir as desigualdades e a vulnerabilidade das famílias.

A gestão de riscos implica na avaliação de possíveis impactos de ações em determinado contexto (GALANTE, 2015). É a busca de proteção para eventos que podem surgir durante a vida e comprometer duramente as finanças e o patrimônio familiar. Uma forma de proteção é o seguro (CVM/PLANEJAR, 2019). É importante compreender como funciona o seguro para tomar decisões corretas na contratação e ter a cobertura adequada (YAKOBOSKI, LUSARDI, HASLER, 2018).

Portanto, a gestão de risco tem sua importância na vida financeira de um indivíduo ou família, como forma de mitigar possíveis riscos, mantendo o equilíbrio financeiro mesmo com a ocorrência de fatos imprevistos. Lusardi, Hasler, Yakoboski (2020) observaram que as áreas de riscos e seguros são de menor conhecimento entre os norte-americanos.

A poupança visa atender às necessidades futuras de renda, tanto no curto como no longo prazo. De maneira geral, $10 \%$ da renda é um bom porcentual para poupar e deveria ser um percentual mínimo, mas caso seja possível poupar mais, sem sacrificar a qualidade de vida, o indivíduo deve fazê-lo (MASSARO, 2018).

O investimento pode ser definido como a aplicação de um recurso com expectativa de um retorno futuro, que seja superior ao capital aplicado (ORIENTE e ALVES, 2016). Há no mercado muitas modalidades de investimentos, tais como caderneta de poupança, fundos, títulos privados e públicos, imóveis, ações, o que exige conhecimento e avaliação para fazer escolhas mais adequadas ao perfil e aos objetivos de cada indivíduo ou família. Apesar das diversas opções de investimentos mais rentáveis, a caderneta de poupança tem sido a modalidade mais popular entre os brasileiros.

A poupança e o investimento são itens importantes das finanças pessoais. Porém, Scholz e Seshardri (2009, apud WILLIS, 2009) argumentam que para famílias de baixa renda, reduzir o consumo atual para poupar e investir, pode causar mais danos que benefícios, visto a condição mínima de sobrevivência às quais muitas famílias estão submetidas.

A aposentadoria é um tema de destaque na alfabetização financeira em muitos países, especificamente no Brasil que, nos últimos dois anos, alterou as regras na legislação previdenciária, aumentando o tempo de contribuição e reduzindo o valor dos benefícios. Para o 
BCB (2013), existem pontos importantes a serem considerados no planejamento da aposentadoria, tais como a expectativa de vida e a incerteza quanto ao futuro.

A previdência no Brasil, segundo o Instituto Nacional de Seguro Social (INSS, 2019), é constituída por três regimes: Regime Próprio de Previdência Social (RPPS), que tem como beneficiários os servidores públicos, Regime Geral de Previdência Social (RGPS), para os demais trabalhadores, e Regime de previdência complementar ou previdência privada. Os dois primeiros são de filiação obrigatória e o terceiro tem adesão facultativa para fins de complemento de renda.

$\mathrm{Na}$ previdência privada aberta, regulada pela Superintendência de Seguros Privados (SUSEP), os planos são ofertados abertamente como uma modalidade de investimento, no entanto, possuem uma estrutura mais complexa. É o caso do Plano Gerador de Benefício Livre (PGBL), principal plano de previdência complementar aberta, geralmente utilizado na complementação de aposentadorias do sistema público. Outra modalidade de plano utilizado com a finalidade de renda futura é o Vida Gerador de Benefício Livre (VGBL). No entanto, este é um seguro de pessoas em que o capital acumulado e capitalizado poderá ser retirado pelo segurado ou seu beneficiário no final de determinado período. A previdência privada fechada ou Fundo de Pensão administra planos de benefícios previdenciários criados por empresas para funcionários é regulada pela Superintendência Nacional de Previdência Complementar (PREVIC) (CVM/PLANEJAR, 2019).

É importante buscar conhecimento para entender as funcionalidades dos planos de previdência e sobre outros investimentos que possam ser incluídos no planejamento para geração de renda futura, tais como ações, títulos públicos e imóveis. Segundo Lusardi; Mitchell (2011); Lusardi, Hasler, Yakoboski (2020), as pessoas com maior nível de alfabetização financeira são mais propensas a poupar e planejar a aposentadoria.

\section{Procedimentos metodológicos}

Esta pesquisa qualitativa com características de descritiva, trabalhou com uma população formada por 94 estudantes matriculados em 4 turmas do curso técnico em Administração do Colégio Estadual de Dois Vizinhos, sudoeste do Paraná, a qual possui alunos do ensino fundamental, médio e profissional. A amostra foi por conveniência e com corte transversal, pois responderam ao questionário 52 estudantes presentes em sala de aula, nos dias em que os dados foram coletados. No entanto, após a coleta e conferência dos questionários, oito foram excluídos por erros de preenchimento, restando 44 válidos ( $47 \%$ da população). A aplicação do questionário ocorreu nos dias 12 e 13 de agosto de 2019. 
O instrumento de coleta de dados foi um questionário estruturado utilizado por Mendes (2018), em pesquisa que analisou hábitos e conhecimento financeiros de professores da rede municipal de um município paranaense. O questionário foi composto por três seções, envolvendo perfil socioeconômico, hábitos financeiros e conhecimento financeiro. Em todas as questões os respondentes poderiam assinalar apenas uma opção de resposta.

A seção sobre hábitos financeiros foi estruturada em três partes, com 17 questões. A primeira, com cinco questões a respeito do uso do dinheiro, planejamento de compras, pesquisa de preços antes de comprar, compras por impulso e verificação de compromissos antes de fazer nova compra. As opções de resposta foram "sempre", "frequentemente", "algumas vezes" e "não". A segunda parte foi composta por nove questões com várias opções de respostas: "o que costuma fazer quando deseja comprar e não tem dinheiro", "prazos de compras", "forma preferida para pagamento de compras", "gastos que tem maior controle", "percentual da renda mensal que costuma poupar", "percentual da renda comprometida com crediário de lojas", "tipo de seguro que possui”, "o que melhor representa sua situação em relação à aposentadoria" e "comprometimento de gastos em relação à renda". A terceira parte composta de três questões dicotômicas (sim e não) acerca de orçamento individual, orçamento familiar e se o respondente possuía reserva de emergência.

A última seção sobre o conhecimento financeiro apresentou nove questões a respeito de definições e conceitos de educação financeira, orçamento familiar, dívidas e juros, controle de dívidas, tipos de dívida, modalidades de créditos, investimento de maior risco, finalidade de seguros e modalidade de previdência complementar. Além das seções acima, foi verificado a principal fonte de conhecimento dos respondentes e uma autoavaliação do conhecimento financeiro, com amplitude de 1 a 5 , onde 1 representava pouco conhecimento e 5 muito conhecimento.

Os dados foram tratados com estatística básica para apuração da frequência em percentual. A análise de hábitos financeiros se pautou nas respostas mais adequadas financeiramente com base na literatura pesquisada, sem atribuição de pontuação. No entanto, em conhecimento financeiro para cada questão respondida corretamente foi atribuído peso 1 e 0 para incorreta, utilizando critério da OECD/INFE, que recomenda acertos de no mínimo $70 \%$ das questões. Para tanto, nesta pesquisa os respondentes precisariam responder corretamente, no mínimo, seis de nove questões para atingirem $70 \%$ de acertos. 


\section{Resultados e discussão}

Os resultados são apresentados em três seções: perfil socioeconômico, hábitos financeiros e conhecimento financeiro.

\section{Perfil socioeconômico}

A amostra foi formada por estudantes do gênero feminino (66\%) e masculino (34\%). A maioria na faixa etária foi de 16 a 21 anos (64\%), contando também com a faixa de 21 a 25 anos $(18 \%)$, de 26 a 30 anos (5\%) de 31 a 35 anos (7\%), e acima de 36 anos (6\%). Solteiros (75\%), casados/união estável $(18 \%)$ e outro tipo de relação $(7 \%)$.

A renda líquida pessoal predominante foi de até dois salários-mínimos $(\mathrm{R} \$ 1.996,00 \mathrm{em}$ 2019), uma representatividade de 72\% dos respondentes. Quanto à renda líquida familiar, a maior concentração foi na faixa entre dois e três salários-mínimos (30\%), seguido de três a quatro salários-mínimos $(27 \%)$, de um a dois salários-mínimos $(23 \%)$ e acima de quatro saláriosmínimos (9\%). Foi representativo o percentual de respondentes que não sabiam a renda familiar (11\%), o que pode indicar ausência ou pouca discussão financeira na família.

\section{Hábitos financeiros}

Referente aos hábitos financeiros verificou-se a atitude dos respondentes no processo de compras, conforme apresentado na tabela 1.

Tabela 1 - Hábitos de compras

\begin{tabular}{l|c|c|c|c|c}
\hline Variável & \multicolumn{4}{|c}{ Frequência } \\
\hline & Sempre & Frequentemente & Algumas vezes & Não & Total \\
\hline $\begin{array}{l}\text { Já lhe ocorreu de não saber } \\
\text { em que foi usado o } \\
\text { dinheiro? }\end{array}$ & $4 \%$ & $5 \%$ & $66 \%$ & $25 \%$ & $100 \%$ \\
\hline Planeja suas compras? & $32 \%$ & $32 \%$ & $32 \%$ & $4 \%$ & \\
\hline $\begin{array}{l}\text { Faz pesquisa de preços } \\
\text { antes de comprar? }\end{array}$ & $27 \%$ & $30 \%$ & $34 \%$ & $9 \%$ & $100 \%$ \\
\hline $\begin{array}{l}\text { Já fez compra por impulso } \\
\text { e depois verificou que } \\
\text { poderia ter deixado para } \\
\text { comprar em outro } \\
\text { momento? }\end{array}$ & $14 \%$ & $11 \%$ & $68 \%$ & $7 \%$ & $100 \%$ \\
\hline $\begin{array}{l}\text { Verifica os compromissos } \\
\text { anteriores fazer nova } \\
\text { compra? }\end{array}$ & $52 \%$ & $16 \%$ & $27 \%$ & $5 \%$ & $100 \%$ \\
\hline
\end{tabular}

Fonte: Autoria própria (2019). 
Quanto ao uso do dinheiro em determinado momento e mais tarde não saber em que foi usado, a maioria dos respondentes (66\%) já fez isso algumas vezes. O mesmo ocorre com compras por impulso (68\%). Uma forma de evitar compras por impulso é sempre verificar os compromissos anteriores, planejar compras e fazer pesquisas de preços, o que foi afirmado por $52 \%, 32 \%$ e $27 \%$ dos respondentes, respectivamente.

Os resultados mostram a necessidade de maior conscientização do consumo para evitar problemas financeiros futuros. Radaelli (2018), em pesquisa com estudantes do ensino superior, concluiu que somente $24 \%$ deles planejavam o consumo. Mendes (2018) verificou que $67 \%$ dos pesquisados compravam por impulso e $20 \%$ tinham essa atitude com frequência.

O consumo de maneira planejada e consciente significa gastar de acordo com a realidade financeira individual ou familiar (BCB, 2013). Para Engel, Blackwell e Miniard (2000, apud BINOTTO et al, 2014), o consumo classifica-se em uma atividade que é diretamente envolvida em obter, consumir e dispor de produtos e serviços, incluindo processos decisórios que antecedem essas ações, além da influência de fatores sociais, culturais e pessoais, principalmente do ambiente no qual o indivíduo está inserido.

Em relação ao comportamento dos respondentes, no tocante ao dinheiro ser insuficiente para o pagamento no momento de uma compra, verificou-se que 37\% deles utilizavam o cartão de crédito e crediários da loja, o que pode ocasionar desequilíbrio financeiro caso não tenham planejamento. Muitos demonstraram bons hábitos ao não comprar (34\%), guardavam dinheiro para comprar à vista posteriormente $(27 \%)$ e outros faziam empréstimos com familiares $(2 \%)$. Mendes (2018) verificou que $52 \%$ das pessoas compravam usando crediário ou cartão de crédito quando não tinham dinheiro suficiente para comprar à vista e $29 \%$ poupavam para comprar depois. Para Kotler e Keller (2006, apud SILVA, 2015), além de fatores culturais, o comportamento do consumidor é influenciado por fatores sociais, como grupos de referência, família, papéis sociais e status, que nesse caso poderia explicar por que mesmo sem dinheiro alguns realizam compras, ainda que de forma parcelada.

Quanto aos meios de pagamento utilizados nas compras, 66\% dos respondentes afirmaram ter preferência por pagamento em dinheiro, 14\% com o cartão de débito, $11 \%$ cartão de crédito e $9 \%$ boletos. Em relação aos prazos de pagamento de compras, verificou-se que a maioria deles preferiam realizar o pagamento à vista (52\%), enquanto $42 \%$ optavam por avaliar o que era mais vantajoso no momento e $6 \%$ preferiam parcelar.

Percebeu-se que havia preferência por pagamento em dinheiro e à vista, resultados que corroboram com achados de Mendes (2018). No entanto, diferem de pesquisa realizada por Silva (2015) com amostra majoritariamente jovem, com faixa etária de 20 até 25 anos (60\%) e de 18 a 
20 anos $(29 \%)$, em que havia predomínio do uso de cartão de crédito $(47 \%)$, seguido de dinheiro $(25 \%)$, crediário $(23 \%)$ e outras formas $(5 \%)$.

Ter o controle de todos os gastos é importante para o equilíbrio financeiro e utilização adequada do dinheiro. Segundo os respondentes, a maioria deles $(63 \%)$ controlava todos os gastos, 18\% faziam apenas controle de gastos domésticos básicos. Aqueles que não faziam nenhum controle foi de 7\%, e que somente controlavam a conta bancária foi de 5\%.

A seguir, na tabela 2, é possível visualizar o hábito dos discentes de poupar, ao apresentar o quanto da renda mensal destina-se à poupança, e atentar para o respectivo percentual de respondentes para cada uma das opções propostas na pesquisa.

Tabela 2 - Percentual da renda mensal que costuma poupar

\begin{tabular}{c|c|c|c|c|c|c}
\hline $\begin{array}{c}\text { Percentual da } \\
\text { renda mensal }\end{array}$ & $\begin{array}{c}\text { Menos } \\
\text { de } \mathbf{1 0} \%\end{array}$ & $\begin{array}{c}\text { De 10\% a } \\
\mathbf{3 0} \%\end{array}$ & $\begin{array}{c}\text { Acima } \\
\text { de } \mathbf{3 0} \%\end{array}$ & $\begin{array}{c}\text { Poupa } \\
\text { eventualmente }\end{array}$ & $\begin{array}{c}\text { Não tem } \\
\text { hábito de } \\
\text { poupar }\end{array}$ & Total \\
\hline $\begin{array}{c}\text { Percentual de } \\
\text { respondentes }\end{array}$ & $11 \%$ & $32 \%$ & $11 \%$ & $21 \%$ & $25 \%$ & $100 \%$ \\
\hline
\end{tabular}

Fonte: Autoria própria (2019).

Verificou-se que $54 \%$ dos respondentes poupavam parte de sua renda regularmente. No entanto, 21\% eventualmente poupavam e $25 \%$ não poupavam. Poupar é necessário para ter segurança financeira, pessoal e/ou familiar, além de possibilitar a realização de objetivos específicos. O percentual de poupança em relação a renda (SILVA et al. 2017a) tem impacto direto no nível de educação financeira dos indivíduos. Quando o indivíduo não poupa não estará preparado para emergências e para a aposentadoria futura.

Segundo o Serviço Brasileiro de Apoio às Micro e Pequenas Empresas (SEBRAE) (2016), a questão não está somente entre poupar ou não poupar, mas também sobre escolhas diárias que devem ser feitas para alcançar sonhos e ter a aposentadoria tranquila, além da educação dos filhos. Para Massaro (2018), de modo geral, 10\% da renda é um bom porcentual e deveria ser o mínimo, mas caso seja possível poupar mais, o indivíduo deve fazê-lo.

$\mathrm{Na}$ tabela 3, observa-se o quanto da renda mensal dos respondentes correspondia a crediários no momento da pesquisa.

Tabela 3 - Quanto da renda mensal é utilizada em crediário

\begin{tabular}{c|c|c|c|c|c|c}
\hline $\begin{array}{c}\text { Percentual da renda } \\
\text { mensal }\end{array}$ & $\begin{array}{c}\text { Menos } \\
\text { de } \mathbf{1 0} \%\end{array}$ & $\begin{array}{c}\text { De } \mathbf{1 0} \% \text { a } \\
\mathbf{3 0} \%\end{array}$ & $\begin{array}{c}\text { Acima } \\
\text { de } \mathbf{3 0} \%\end{array}$ & $\begin{array}{c}\text { Não compra } \\
\text { a prazo }\end{array}$ & $\begin{array}{c}\text { Não } \\
\text { sabe }\end{array}$ & Total \\
\hline $\begin{array}{c}\text { Quanto costuma pagar } \\
\text { de crediário (lojas) }\end{array}$ & $32 \%$ & $18 \%$ & $9 \%$ & $25 \%$ & $16 \%$ & $100 \%$ \\
\hline
\end{tabular}

Fonte: Autoria própria (2019). 
A maior parte dos respondentes (32\%) comprometia menos de $10 \%$ da renda em crediários, $25 \%$ não compravam a prazo, mostrando controle mais rigoroso de dívidas. Entretanto, para 9\% deles havia maior comprometimento da renda e 16\% afirmaram não saber. Nestes dois últimos grupos denota-se ausência de controle. Os gastos com crediários, se mal administrados e não planejados, levam ao endividamento, comprometendo o orçamento.

Comprometer grande percentual da renda com crediário não é recomendável, uma vez que as pessoas já possuem gastos domésticos importantes, além da necessidade de poupar parte da renda para imprevistos e para atingir objetivos de longo prazo. Segundo BCB (2013), devido a fatores como incerteza quanto ao futuro, aumento do custo de vida e concretização de sonhos é necessário estar preparado para necessidades que podem surgir.

Em relação a seguros, a maioria (65\%) dos respondentes não possuía, 21\% tinham seguro de vida, $7 \%$ possuíam mais de um tipo de seguro, $5 \%$ seguro de veículo e $2 \%$ seguro residencial. Quanto ao planejamento de aposentadoria verificou-se que 56\% dos respondentes não estavam preocupados, 18\% tinham planos de previdência complementar, 14\% investiam ou investiriam em imóveis para ter renda de aluguel no futuro, $7 \%$ pretendiam ter somente a previdência pública e 5\% faziam investimentos financeiros para ter complemento de renda na aposentadoria.

Portanto, o planejamento de aposentadoria, de modo geral, é inexistente. Esse resultado corrobora com achados de Mendes (2018) em que 38\% das pessoas não se preocupavam com aposentadoria e 35\% afirmaram pretensão de ter somente a aposentadoria pública, e da CNDL/SPC (2019) ao relatar que 75\% dos jovens de 18 a 24 anos não se preocupavam com aposentadoria. Dentre os motivos estavam renda insuficiente e o fato de serem muito jovens.

Para França; Murta; Iglesias (2014), a aposentadoria ocorre, na maioria das vezes, juntamente com o processo de envelhecimento, causando grandes transformações na vida das pessoas, por isso é importante que desde cedo os jovens se preocupem e comecem a planejá-la. Lusardi e Mitchell (2011) comentam que o planejamento para a aposentadoria ganha importância à medida em que aumenta a idade.

Observando o comprometimento de gastos em relação à renda percebe-se que 45\% dos respondentes estavam incapacitados de pôr em prática um plano de aposentadoria voluntária. Entre eles, estavam aqueles que possuíam gastos iguais a renda, outros tinham gastos maiores que a renda e alguns não possuíam renda. Entretanto, os demais (55\%) tinham gastos menores que a renda. Fernandes e Candido (2014), em pesquisa com universitários, observaram que 59\% dos respondentes comprometiam menos de 30\% da renda com gastos.

Nas três questões dicotômicas que poderiam ser respondidas "sim" ou "não" sobre a existência de orçamento individual, orçamento familiar e reserva de dinheiro para imprevistos, 
verificou-se que tais hábitos eram adotados por 55\%, 45\% e $68 \%$ dos respondentes, respectivamente. Em Mendes (2018), 71\% das pessoas possuíam orçamento pessoal, 78\% orçamento familiar e 77\% possuíam reserva de emergência. Pesquisa da OECD/INFE (2016) mostrou que para muitos, o orçamento não é uma prioridade, apesar de ser um instrumento de controle e planejamento financeiro.

\section{Conhecimentos financeiros}

Esta seção teve como objetivo averiguar o conhecimento financeiro com questões envolvendo definição e conceitos de educação financeira, orçamento, dívidas, risco em investimentos, seguros e previdência complementar, cujas opções de respostas constavam opções afirmativas, em que apenas uma poderia ser escolhida.

Os acertos representam o percentual de estudantes que respondeu corretamente cada questão. Observa-se que a maioria deles, $75 \%$ a $98 \%$, respondeu corretamente apenas cinco de nove questões, o que representa nível de acertos de 56\%. Os estudantes demonstraram ter conhecimento sobre a importância do orçamento familiar, custos e juros de dívidas, tipos de dívidas no âmbito familiar, melhor ação para controle de dívidas e investimento de maior risco, conforme demonstrado no quadro 1.

\section{Quadro 1 - Conhecimento financeiro}

\begin{tabular}{|l|l|c|}
\hline \multicolumn{1}{|c|}{ Questão } & \multicolumn{1}{|c|}{ Resposta correta } & Acertos \\
\hline Sobre Educação Financeira. & Todas as opções estão corretas. & $41 \%$ \\
\hline $\begin{array}{l}\text { Sobre orçamento financeiro } \\
\text { familiar. }\end{array}$ & $\begin{array}{l}\text { É importante para que todas as pessoas ou famílias } \\
\text { possam administrar melhor suas finanças pessoais ou } \\
\text { familiares. }\end{array}$ & $98 \%$ \\
\hline Sobre custos de dívidas e juros. & $\begin{array}{l}\text { O valor total de uma dívida será maior se a dívida for } \\
\text { paga em muitas parcelas. }\end{array}$ & $96 \%$ \\
\hline $\begin{array}{l}\text { Melhor ação para manter o } \\
\text { controle regular das dívidas. }\end{array}$ & $\begin{array}{l}\text { Consultar sempre as dívidas assumidas para poder } \\
\text { decidir se pode ou não assumir outros compromissos. }\end{array}$ & $84 \%$ \\
\hline O que representa dívida. & Todas as opções estão corretas. & $93 \%$ \\
\hline $\begin{array}{l}\text { Tipo de crédito (empréstimo) que } \\
\text { tem a menor taxa de juros. }\end{array}$ & Empréstimo consignado. & $39 \%$ \\
\hline $\begin{array}{l}\text { Tipo de investimento que possui } \\
\text { maior risco. }\end{array}$ & Ações. & $75 \%$ \\
\hline Finalidade de seguros. & Proteger o patrimônio e as pessoas de possíveis riscos. & $61 \%$ \\
\hline $\begin{array}{l}\text { Representa previdência } \\
\text { complementar. }\end{array}$ & Plano Gerador de Benefício Livre (PGBL). & $14 \%$ \\
\hline
\end{tabular}

Fonte: Autoria própria (2019). 
O percentual de acertos encontrado nesta pesquisa está próximo daquele encontrado por Chen e Volpe (1998), em pesquisa realizada com estudantes universitários norte-americanos, quando o resultado foi de aproximadamente 53\% de acertos; os estudos de Lusardi, Hasler, Yakoboski (2020) também revelaram que norte-americanos responderam corretamente apenas $52 \%$ das questões propostas em diversas áreas financeiras, o que, segundo os autores, é nota de reprovação. Tal comparação mostra que, mesmo após décadas, o conhecimento financeiro ainda é baixo.

Individualmente, outras quatro questões tiveram menos acertos, ou seja, poucos estudantes acertaram as respostas, o que representa conhecimento financeiro insuficiente. Sobre a finalidade de seguros, $61 \%$ dos respondentes acertaram. Nas questões a respeito da definição e conceito de educação financeira, taxa de juros de empréstimos e modalidade de previdência complementar, os acertos foram de $41 \%, 39 \%$ e $14 \%$, respectivamente.

A contração de seguros é importante à medida que contribui para redução de perdas financeiras e comprometimento do orçamento se houver algum sinistro. Quanto ao conceito de educação financeira, observou-se que os respondentes possuem uma visão restrita do tema, condição que reforça a justificativa do aprendizado financeiro nas escolas. Chen, Volpe (1998); Yakoboski, Lusardi, Hasler (2018) observaram que os jovens possuíam pouco conhecimento sobre seguros.

A questão sobre previdência complementar obteve o menor índice de acertos, apenas 14\%. A opção "não sei responder" foi de $77 \%$, o que reflete o pouco interesse no planejamento de aposentadoria, conforme visto anteriormente, em que 56\% dos respondentes afirmaram não estar preocupados e outros 7\% teriam somente o benefício de aposentadoria oficial pública, o que é preocupante, pois é preciso planejar a aposentadoria desde cedo. Estes resultados corroboram com a pesquisa de Mendes (2018), que revelou pouco conhecimento sobre previdência complementar, pouca preocupação com a aposentadoria e pretensão de ter apenas a aposentadoria pública.

Quanto ao aprendizado acerca do conhecimento financeiro, a principal fonte foi a família (46\%), a escola (34\%), TV, rádio, internet (18\%) e amigos (2\%). Vieira; Bataglia; Sereia, (2011) e Mendes (2018) mostraram em suas pesquisas que a família se destaca como principal fonte para $43 \%$ e $52 \%$, respectivamente. Silva et al. (2017b) verificaram que $70 \%$ adquiriram conhecimento financeiro com a família e experiências práticas.

$\mathrm{Na}$ autoavaliação para administrar o próprio dinheiro, os respondentes poderiam escolher uma entre cinco opções de respostas (1 a 5), em que 1 representava pouco conhecimento, e 5 muito conhecimento. A maioria deles (64\%) atribuiu a si pontuação de 1 a 3 . Os demais (36\%) se 
autodeclararam ter mais conhecimento, atribuindo a si 4 ou 5. A autoavaliação comparada ao resultado da avaliação de conhecimentos financeiros (56\% de acertos), mostra coerência e demonstra a necessidade de melhorar o nível de alfabetização financeira. Lusardi e Mitchell (2011) relatam que, geralmente, as pessoas tendem a superestimar o quanto sabem, por desconhecer suas próprias deficiências. A autoavaliação deve ser considerada como uma medida de confiança ou excesso de confiança e não como alfabetização (WILLIS, 2009).

\section{Considerações finais}

O estudo teve como objetivo principal avaliar a alfabetização financeira de estudantes do curso técnico em Administração do Colégio Estadual de Dois Vizinhos, sudoeste do Paraná. Participaram da pesquisa 44 estudantes, a maior parte do gênero feminino (66\%), idades de 16 a $21 \operatorname{anos}(64 \%)$ e solteiros $(75 \%)$.

De modo geral, os respondentes possuíam bons hábitos financeiros em relação ao orçamento e compras, verificando preços e compromissos anteriores, mas algumas vezes compravam por impulso $(68 \%)$ e não se lembravam como usaram o dinheiro (66\%). Também foi possível notar que havia preferência por pagamentos de compras à vista $(52 \%)$ ou verificavam o que era mais vantajoso no momento da compra (41\%).

Em relação ao controle de gastos, $63 \%$ dos respondentes disseram controlar todas as contas, o que é importante para as finanças pessoais. A poupança mostrou ser um hábito para $32 \%$ deles e $68 \%$ tinham reserva financeira. No entanto, os resultados críticos foram verificados em seguros e planejamento de aposentadoria, itens ausentes para $65 \%$ e $56 \%$ dos respondentes, respectivamente. A ausência de seguros pode comprometer o patrimônio e desiquilibrar as finanças, caso ocorra um sinistro e a despreocupação com o planejamento da aposentadoria compromete a vida financeira no futuro, quando não houver mais a capacidade de trabalho para o sustento individual ou familiar. O fato de a maioria dos respondentes serem jovens e a limitação ou a ausência de renda podem estar contribuindo para esses resultados.

Do conhecimento financeiro sobre orçamento; dívidas e juros; controle de dívidas; o que representa dívida e investimento de maior risco, a maioria dos estudantes, $75 \%$ a $98 \%$, responderam corretamente estas questões, o que representa nível de acertos de $56 \%$, ou seja, a maioria acertou apenas cinco de nove questões. Apenas 61\% deles responderam corretamente sobre a finalidade de seguros. As questões que trataram da definição de educação financeira, crédito que possui a menor taxa de juros e modalidade de previdência complementar, os percentuais de acertos foram baixos. Para os respondentes, a principal fonte de conhecimento financeiro foi a família (46\%), seguido da escola (34\%), Tv, rádio, internet (18\%) e amigos (2\%). 
Avalia-se que os respondentes ainda necessitam adquirir novos conhecimentos e novos hábitos financeiros para se tornarem efetivamente alfabetizados financeiramente. Entretanto, Huston (2010) argumenta que uma medida de alfabetização financeira identifica o conhecimento financeiro necessário para que a pessoa o aplique adequadamente, mas não garante que isso ocorra. De modo que não é possível afirmar que pessoas com situações financeiras abaixo do ideal são necessariamente analfabetas financeiramente.

Embora o instrumento de pesquisa seja formado por questões básicas sobre hábitos e conhecimento financeiros, bem como em razão da amostra não ser probabilística, a realização do estudo trouxe resultados importantes para a escola, bem como para uma reflexão, por se tratar de estudantes do curso técnico em Administração e pela importância das finanças no contexto individual e familiar, podendo, inclusive, auxiliá-los profissionalmente na gestão financeira empresarial.

\section{Referências}

ATKINSON, Adele.; MESSY, Flore-Anne. Measuring Financial Literay: results of the OECD INFE pilot study. Paris: OECD/INFE, 2013. Disponível em <https://dx.doi.org/10.1787/5k9csfs90fr4-en> Acesso em: 26 jul. 2020

BANCO CENTRAL DO BRASIL (BCB). Caderno de Educação Financeira Gestão de Finanças Pessoais. (Conteúdo Básico). Brasília: BCB, 2013. Disponível em: http://www.bcb.gov.br/pre/pef/port/caderno_cidadania_financeira.pdf. Acesso em: 23 mar, 2018.

Estatísticas monetárias e de crédito. Brasília: BCB, 2019. Disponível em:

<https://www.bcb.gov.br/estatisticas/estatisticasmonetariascredito>. Acesso em: 16 maio 2019.

BINOTTO, Simone, et al. Os fatores de influência no comportamento do consumidor: um estudo em uma cooperativa agrícola do RS. Revista de Gestão e Organizações Cooperativas - Rgc. Santa Maria, v. 01, n. 02, p.01-14, fev. 2014.

BRASIL. Decreto No 7.397, de 22 de dezembro de 2010. Diário Oficial da União. Brasília. Disponível em: <http://www.planalto.gov.br/ccivil_03/_Ato2007-

2010/2010/Decreto/D7397.htm.> Acesso em: 01 abr. 2019.

Decreto $\mathrm{N}^{\circ}$ 10.393, de 9 de junho de 2020. Diário Oficial da União. Brasília.

Disponível em: < http://www.planalto.gov.br/ccivil_03/_ato2019-

2022/2020/decreto/D10393.htm>. Acesso em: 18 ago. 2020.

FERNANDES, André H. de Souza; CANDIDO, João. G.; Educação financeira e nível do endividamento: relato de pesquisa entre os estudantes de uma instituição de ensino da cidade de São Paulo. Revista Eletrônica Gestão e Serviços. São Paulo, v. 5, n. 2, p. 894-913, 2014. 
Disponível em: < https://doi.org/10.15603/2177-7284/regs.v5n2p894-913>. Acesso em: 21 maio 2019.

CHEN, Haiyang; VOLPE. Ronald P. An Analysis of Personal Financial Literacy Among College Students. 1998. Financial Services Review. Disponível em:

$<$ https://www.cgsnet.org/ckfinder/userfiles/files/An_Analysis_of_Personal_Financial_Lit_Am ong_College_Students.pdf>. Acesso em: 16 jul. 2020.

COMISSÃO DE VALORES MOBILIÁRIOS (CVM); ASSOCIAÇÃO BRASILEIRA DE PLANEJADORES FINANCEIROS (PLANEJAR). Rio de Janeiro: CVM, 2019. Disponível em $<$ https://www.investidor.gov.br/portaldoinvestidor/export/sites/portaldoinvestidor/publicacao /Livro/livro_TOP_planejamento_financeiro_pessoal.pdf>. Acesso em: 13 out. 2019.

CONFEDERAÇÃO NACIONAL DE DIRIGENTES LOJISTAS (CNDL); SERVIÇO DE PROTEÇÃO AO CRÉDITO (SPC). $47 \%$ dos jovens da Geração $\mathbf{Z}$ não realizam o controle das finanças. 2019. Disponível em: https://www.spcbrasil.org.br/pesquisas>. Acesso em: 20 jun. 2019.

FRANÇA, Cristineide. L.; MURTA, Sheila.G.; IGLESIAS, Fabio. Planejamento da aposentadoria: uma escala de mudança de comportamento. Revista Brasileira de Orientação Profissional. São Paulo, v. 15, n. 01, p.75-84, jun. 2014. Disponível em: <https://www.redalyc.org/pdf/2030/203035764009.pdf>. Acesso em: 04 nov. 2019.

FRANKENBERG, Louis. Seu Futuro Financeiro. Rio de Janeiro: Ed. Campus. 1999.

GALANTE, Erick. B. Ferrão. Princípios da Gestão de Risco. Curitiba: Appris, 2015.

HALFELD, Mauro. Investimentos: como administrar melhor seu dinheiro. São Paulo: Fundamento Educacional, 2006.

HILGERT, Marianne A.; HOGARTH, Jeanne.M.; BEVERLY, Sondra.G. Household Financial Management: The Connection between Knowledge and Behavior. Federal Reserve Bulletin. Washington, 2003. Disponível em: $<$ https://pfeef.org/wp-content/uploads/2016/09/FED-Needs-Impact-07-03-HilgartHogarth.pdf $>$. Acesso em: 21 jun. 2020.

HUSTON, Sandra J. Measuring Financial Literacy. The Journal of Consumer Affairs. 2010. Disponivel em: <https://onlinelibrary.wiley.com/doi/epdf/10.1111/j.17456606.2010.01170.x.>. Acesso em: 20 maio 2019.

INSTITUTO NACIONAL DE SEGURO SOCIAL (INSS). Regimes de Previdência: RPPS, RGPS e RPC. Brasilia, 2019. Disponível em: <https://tabeladoinss2019.com/regimes-deprevidencia-rpps-rgps-rpc/>. Acesso em: 21 maio 2019.

LIZOTE, Suzete A.; LANA, Jeferson; SIMAS, Jaqueline de. Finanças Pessoais: um estudo envolvendo os alunos de Ciências Contábeis de uma instituição de ensino superior de Santa Catarina. 2012. Disponível em:

<https://www.aedb.br/seget/arquivos/artigos12/10216156.pdf>. Acesso em: 24 maio 2019. 
LUSARDI, Annamaria. Numeracy, Financial Literacy, and Financial Decision-making. 2012.

National Bureau of Economic Research. Disponível em:

<http://www.nber.org/papers/w17821>. Acesso: 20 maio 2020.

LUSARDI, Annamaria.; HASLER, Andrea.; YAKOBOSKI, Paul.J. Building up financial literacy and financial resilience. 2020. Mind \&Society. Disponível em:

$<$ https://doi.org/10.1007/s11299-020-00246-0>. Acesso em: 04 jun. 2021.

LUSARDI, Anamaria.; MITCHELL, Olivia S. Financial Literacy and Retirement Planning in the United States. 2011. National Bureau of Economic Research Disponível em:

<http:/www.nber.org/papers/w17108>. Acesso em: 20 maio 2020.

The Economic Importance of Financial Literacy. Journal of Economic Literature.

2013. Disponivel em: < https://www.bde.es/f/webpi/SES/seminars/2014/files/sie1401.pdf.> Acesso em: 20 jun. 2020.

MASSARO, André. Afinal, quanto da renda mensal devemos guardar? São Paulo, 2018. Disponível em: <https://exame.abril.com.br/blog/voce-e-o-dinheiro/afinal-quanto-da-rendamensal-devemos-guardar/>. Acesso em: 20 set. 2019.

MENDES, Everton L. Camargo. Educação financeira: estudo com professores de um município do Sudoeste do Paraná. 2018. 51 f. TCC (Graduação) - Curso de Administração, Universidade Estadual do Oeste do Paraná, Francisco Beltrão, 2018.

ORGANISATION FOR ECONOMIC CO-OPERATION AND DEVELOPMENT (OECD). Improving Financial Literacy: Analysis of Issues and Policies. Paris, 2005. Disponivel em <https://doi.org/10.1787/9789264012578-en>. Acesso em: 3 jul. 2020.

ORGANISATION FOR ECONOMIC CO-OPERATION AND DEVELOPMENT (OECD) INTERNATIONAL NETWORK ON FINANCIAL EDUCATION (INFE). Measuring Financial Literacy: Core Questionnaire in Measuring Financial Literacy: Questionnaire and Guidance Notes for conducting an Internationally Comparable Survey of Financial literacy. Paris, 2011. Disponível em: <https://www.oecd.org/finance/financialeducation/49319977.pdf>. Acesso em: 26 de jul. 2020

National strategies for Financial Education: OECD/INFE Policy Handbook. Paris, 2015. Disponível em: < http://www.oecd.org/daf/fin/financial-education/NationalStrategies-Financial-Education-Policy-Handbook.pdf> . Acesso em: 25 maio 2019.

International Survey of Adult Financial Literacy Competencies. Paris, 2016. Disponivel em: <www.oecd.org/finance/OECD-INFE-International-Survey-of-Adult-FinancialLiteracy-Competencies.pdf>. Acesso em: 5 maio 2020.

ORIENTE, Anderson C. Nogueira; ALVES, Leandro. Oliveira. Investimentos: um estudo de caso na formação de poupança dos jovens universitários. 2016. Disponível em: <https://www.aedb.br/seget/arquivos/artigos17/28225319.pdf>. Acesso em: 25 maio 2019.

POTRICH, Ani. C. Grigion; VIEIRA, Kelmara Mendes; KIRCH, Guilherme. Determinantes da Alfabetização Financeira: Análise da Influência de Variáveis Socioeconômicas e Demográficas. 2014. Disponível em: < http://www.scielo.br/pdf/rcf/v26n69/1808-057x-rcf-2669-00362.pdf>. Acesso em: 22 maio 2019. 
POTRICH, Ani. C. Grigion; VIEIRA, Kelmara Mendes; KIRCH, Guilherme. Você é Alfabetizado Financeiramente? Descubra no Termômetro de Alfabetização Financeira. BASE Revista de Administração e Contabilidade da UNISINOS. v. 13, n. 2, p. 153-170, 2016. Disponível em http://www.spell.org.br/documentos/ver/42226/voce-e-alfabetizadofinanceiramente--descubra-no-termometro-de-alfabetizacao-financeira/i/pt-br. Acesso em: 01 set. 2020.

RADAELLI, Fabiola. Estudo sobre as finanças pessoais dos alunos de Ciências Contábeis de uma instituição de ensino superior do Vale do Taquari. 2018. 58 f. TCC (Graduação) Curso de Ciências Contábeis, Universidade do Vale do Taquari - Univates, Lajeado, 2018. Disponível em: <https://www.univates.br/bdu/bitstream/10737/2090/1/2018Fab\%C3\%ADolaRadaelli.pdf>. Acesso em: 05 nov. 2019.

SECURATO, José R. Análise e avaliação de risco: pessoas físicas e jurídicas. São Paulo: Editora Atlas, 2002.

SERVIÇO BRASILEIRO DE APOIO ÀS MICRO E PEQUENAS EMPRESAS (SEBRAE). O Hábito de poupar. Brasília: Sebrae, 2016. 30 p. Disponível em: $<$ https://bibliotecas.sebrae.com.br/chronus/ARQUIVOS_CHRONUS/bds/bds.nsf/c5531c60 27adc145277e81784810c3c7/\$File/7219.pdf>. Acesso em: 01 nov. 2019.

SILVA, Yasmin. P. Pereira. Comportamento do Consumidor: análise das variáveis mais significativas no processo de compra da geração Y em São Paulo. Revista Anagrama: Revista Científica Interdisciplinar da Graduação, São Paulo, v. 2, n. 9, p.2-17, jul. 2015.

SILVA, Guilherme de Oliveira e, et al. Alfabetização Financeira versus Educação Financeira: Um Estudo do Comportamento de Variáveis Socioeconômicas e Demográficas. Revista de Gestão, Finanças e Contabilidade. Salvador, v. 7, n. 3, p. 279-298, 2017a. Disponível em: $<$ https://www.revistas.uneb.br/index.php/financ/article/view/3726/2444>. Acesso em: 01 nov. 2019.

SILVA, Tarcísio Pedro, et al. Financial education level of high school students and its economic reflections. Rev. Adm. [online]. São Paulo, vol.52, n.3, pp.285-303. ISSN 1984-6142, 2017b. Disponível em: <http://dx.doi.org/10.1016/j.rausp.2016.12.010>. Acesso em: 19 maio 2019.

VIEIRA, Saulo F.Amancio; BATAGLIA, Regiane T. Manfre; SEREIA, Vanderlei José. Educação Financeira e Decisões de Consumo, Investimento e Poupança: uma Análise dos Alunos de uma Universidade Pública do Norte do Paraná. Revista de Administração da UNIMEP. v. 9, n. 3, p. 61-86, 2011

YAKOBOSKI, Paul.J; LUSARDI, Annamaria.; HASLER, Andrea. Millennial Financial Literacy and Fin-tech Use: Who Knows hat in the Digital Era. 2018. Disponível em $<$ https://www.tiaainstitute.org/sites/default/files/presentations/2018-09/TIAA\%20InstituteGFLEC_Millennial\%20P-Fin\%20Index_September\%202018.pdf>. Acesso em 26 Nov. de 2020.

WACHIRA, Mwangi Isaac; KIHIU, Evelyne Nyathira. Impact of financial literacy on access to financial Services in Kenya. International Journal of Business and Social Science., v. 3, n. 19, 2012. Disponível em: <http://www.ijbssnet.com/journals/ >. Acesso em: 29 abr. 2019. 
WILLIS, Lauren E. Evidence and Ideology in Assessing the Effectiveness of Financial Literacy Education. Law School Journals at Digital USD. San Diego, 2009. Disponível em:

$<$ https:/ /digital.sandiego.edu/cgi/viewcontent.cgi?article $=2715 \&$ context $=$ sdlr $>$. Acesso em: 03 jun. 2020.

Recebido em: 26 de novembro de 2020. Aprovado em: 28 de maio de 2021. 